\title{
Equilibrium Price Dispersion in Retail Markets for Prescription Drugs
}

\author{
Alan T. Sorensen \\ University of California, San Diego
}

\begin{abstract}
This study seeks to establish the empirical importance of price dispersion due to costly consumer search by examining retail prices for prescription drugs. Posted prices in two geographically distinct markets are shown to vary considerably across pharmacies within the same market, even after one controls for variation due to pharmacy differences. Pharmacy heterogeneity accounts for at most one-third of the observed price dispersion. The empirical analysis hinges on the observation that consumers' incentives to price-shop depend on characteristics of the drug therapy. Cross-sectional patterns in price distributions across drugs are consistent with the predictions of a search model: prices for repeatedly purchased prescriptions (for which the expected benefits of search are highest) exhibit significant reductions in both dispersion and price-cost margins.
\end{abstract}

\section{Introduction}

The proverbial "law of one price" is virtually never empirically valid. Homogeneous goods are often sold at widely different prices by rival firms, even in environments that seem particularly conducive to economic competition. Following a seminal paper by Stigler (1961), several economists developed information-based models explaining this phenomenon (see, e.g., Salop and Stiglitz 1982; Burdett and Judd 1983; Stahl 1989). The principal success of this literature was to identify conditions under which price dispersion can arise as a stable equilibrium

I am very grateful to Glenn Ellison and Nancy Rose for their careful comments on previous versions of this paper. I also thank Ernst Berndt, Paul Joskow, Whitney Newey, an anonymous referee, and seminar participants at various universities for helpful suggestions and discussion.

[Journal of Political Economy, 2000, vol. 108, no. 4]

(C) 2000 by The University of Chicago. All rights reserved. 0022-3808/2000/10804-0008 $\$ 02.50$ 
outcome. Generally speaking, price dispersion will arise when there is a positive (but uncertain) probability that a randomly chosen customer knows only one price. Thus, even in markets with symmetric firms selling homogeneous products, prices may differ in equilibrium if consumers must incur search costs to obtain price information.

This paper seeks to demonstrate the empirical importance of price dispersion that arises from imperfect information by examining the retail market for prescription drugs. Using data collected from individual pharmacies in upstate New York, I show that cash prices for equivalent prescriptions differ substantially across pharmacies within the same small town. On average, the highest posted price for a given prescription is over 50 percent above the lowest available price. The benefits of price shopping can be substantial even in absolute terms: the potential savings from finding the lowest-cost pharmacy (as measured by the price range across pharmacies) exceed $\$ 10$ for over half of the prescriptions in the sample.

Differences in pharmacy service or location do not appear to explain fully the observed price variation. Pharmacies' price rankings are inconsistent across drugs, and hedonic regressions using pharmacy service characteristics as explanatory variables are relatively unsuccessful in explaining price differences. I estimate that pharmacy effects account for at most one-third of the variation in drug prices about their means.

The central finding of this study is that observed price distributions are consistent with the predictions of models based on consumer search. The empirical approach hinges on the observation that incentives to price-shop are strongest for prescriptions that must be purchased frequently, such as medications used to treat chronic conditions. Consumers' increased propensities to price-shop for frequently purchased prescriptions should lead to less absolute dispersion and lower markups for such prescriptions. This prediction is found to be true in the data: measures of both dispersion and markups are significantly lower for drugs that are purchased repeatedly. Price ranges for one-time prescriptions are estimated to be 34 percent larger than those for prescriptions that must be purchased monthly. Absolute markups (which are inferred from average wholesale price data) for one-time prescriptions are estimated to be 41 percent higher than those for prescriptions purchased monthly, other things being equal.

Two previous empirical studies have explicitly addressed the role of consumer search in explaining price dispersion. ${ }^{1}$ Dahlby and West (1986) use data on prices for auto insurance policies to test the predictions of a dispersion model due to Carlson and McAfee (1983) and

\footnotetext{
${ }^{1}$ Other studies that have examined data on dispersion include Pratt, Wise, and Zeckhauser (1979) and Villas-Boas (1995).
} 
ultimately conclude that the dispersion in premiums can be explained by costly consumer search. Their finding that premiums are least dispersed in driver classes in which search is most likely to occur is similar to the results discussed in the present study. However, they also find that premiums at a given firm are highly correlated across driver classes, in contrast to the finding here that prices at a given pharmacy are at most weakly correlated across drugs. In another study, Van Hoomissen (1988) examines price data from Israel during an inflationary period and attempts to distinguish between dispersion based on product differences and dispersion based on imperfect information. She finds that inflation (which is linked to reductions in the value of acquiring price information) is positively related to dispersion and interprets the finding as evidence that price dispersion arises from imperfect consumer information. Although this paper reaches a similar conclusion, it differs from Van Hoomissen's study in that it exploits cross-sectional variation instead of time variation to identify the effects of search and information, and it directly addresses the role of product heterogeneity in generating dispersion. Moreover, price data in this paper come from stores competing within well-defined local markets, so the results can be more appropriately interpreted in the context of equilibrium price dispersion models.

\section{Theoretical Framework}

The central proposition of this study is that consumers' increased propensities to price-shop for repeatedly purchased prescriptions will constrain the prices of such prescriptions to be lower and less dispersed. ${ }^{2}$ That increases in search intensity will lead to lower prices and less dispersion is a common and intuitive finding in the theoretical literature on price dispersion. Consider a firm that is charging a price that is high relative to rival firms' prices. This firm can expect to make sales only if there is some probability that a randomly arriving consumer has not obtained a lower price quote and that such a consumer will choose to purchase rather than incur the cost of seeking additional price quotes. If search intensity increases (e.g., because of a reduction in search costs), firms' incentives to raise prices are diminished since such prices are more likely to be rejected in favor of searching for a lower price.

Why should consumers be more inclined to price-shop for prescriptions they anticipate purchasing frequently? The value of finding a pharmacy with a low price is clearly magnified for repeatedly purchased

\footnotetext{
${ }^{2}$ For a more detailed discussion of a search model that generates this prediction, see an earlier version of this paper (Sorensen 1999). The effects of repeated purchasing on search market equilibria are also considered in separate treatments by Fishman and Benabou (1993) and Rob (1995).
} 
prescriptions since the savings from having done so can be realized multiple times. However, in addition to the size of the total expected purchase, the frequency with which a prescription is purchased is also an important element of the search decision. Consumers will expect that after some amount of time, a pharmacy previously identified as the lowprice pharmacy will no longer have the lowest price. Frequency of purchase can be regarded as measuring the number of times the information gained from a price search can be used before that information "expires." ${ }^{3}$ Therefore, other things being equal, the benefit per search is highest for prescriptions that consumers expect to purchase frequently. ${ }^{4}$

Search-based explanations of price dispersion also suggest that dispersion and markups should move together in response to variation in the search environment: changes in the intensity of search that lead to lower prices will also reduce dispersion through the same market mechanisms. Since search decisions depend on a variety of factors, variation in dispersion and markups left unexplained by observable prescription characteristics should exhibit positive correlation.

\section{Data}

\section{A. Collection}

Empirical examination of patterns in dispersion and margins for prescription drugs requires data on prices across competing pharmacies within defined markets. Although most pharmacists willingly quote cash prices over the phone, few would be willing to do so for a large number of drugs, so assembling data through a phone survey was impractical. However, state legislation in New York requires all pharmacies to post their prices for 152 top-selling prescriptions. ${ }^{5}$ The prices are posted and updated on a large poster provided by the State Board of Pharmacy.

\footnotetext{
${ }^{3}$ For repeat purchasing to affect search incentives, consumers must expect prices to be stable over some period of time. While the cross-sectional data analyzed here can provide no evidence regarding the stability of prices over time, transactions data from other localities used in related research indicate that prescription prices indeed remain somewhat stable over periods of up to six months (Sorensen 1999). However, since different pharmacies change their prices at different times, it is also reasonable to expect that pharmacies' relative price rankings will change from period to period.

${ }^{4}$ Retail Pharmacy Practice Management, a 1989 pharmacy management guide published by the National Association of Retail Druggists, indicates that pharmacists indeed consider the demand implications of repeat purchasing when setting prices: "Acute drugs are usually purchased for infection or pain and do not have a very high refill ratio. Consumers tend not to comparison shop for these prescriptions, which decreases the drugs' price sensitivity. On the other hand, chronic drugs are taken over a long period of time so consumers are more price-conscious with these items, which increases market sensitivity" (p. 479).

${ }^{5}$ When applicable, the price for the generic version of the prescription is also posted, so the total number of separate prescriptions for which prices are listed is roughly 240.
} 
The data used in this paper were copied directly from the posters of 20 pharmacies in Middletown and Newburgh, New York in March 1998. ${ }^{6}$ Data regarding pharmacy characteristics are based on my observations from visiting the pharmacies as well as brief conversations with the pharmacists themselves.

The cities of Middletown and Newburgh were selected for a number of reasons. Both cities have a moderate number of pharmacies (10 and 11, respectively) and are geographically isolated, so the set of local pharmacies can reasonably be regarded as the universe of available options to local shoppers. For instance, each of the 10 pharmacies in Middletown is within a four- or five-minute drive of all the others, but the closest pharmacy beyond these 10 is at least a 20-minute drive away.

The price-posting legislation dictates that any posted price must be honored at the request of the consumer. Pharmacists thus have an incentive to update the posted prices frequently, lest a consumer insist they honor an outdated (and presumably lower) price. At the time of the data collection, most of the pharmacies had updated their prices within the month; however, data from one of the pharmacies in Newburgh were dropped because the pharmacist said he had not updated the prices in over three months. One other independent pharmacy in Newburgh is also excluded from the data set since the pharmacist inhospitably interfered with the data collection.

Data on drug characteristics were collected from Mosby's GenRx (1998), a large pharmaceutical reference manual. For each drug, information was collected on its primary use (i.e., asthma, arthritis, etc.), the typical dosage, and duration of therapy. For use in constructing cost measures, average wholesale prices (AWP) were also collected. ${ }^{7}$

\section{B. Summary of Price Variation across Pharmacies}

The fact most clearly confirmed by the data is that prescription prices vary considerably across pharmacies. (It is important to note that differences in posted prices are primarily relevant for cash-paying customers. Customers with insurance coverage typically pay the same out-ofpocket price at any "in-network" pharmacy since contracted rates established by insurers-which are not generally equal to posted prices-differ little across pharmacies.) The magnitudes of price differences faced by cash customers are substantial: the range of posted

\footnotetext{
${ }^{6}$ Prescriptions for which prices were posted at fewer than four of a city's pharmacies were excluded from the data set, as were prescriptions that had become available over the counter since the publication of the price poster. The final data set consists of 428 prescriptions: 224 in Middletown and 204 in Newburgh.

${ }^{7}$ The lowest-listed AWP was used since industry information suggests that this is the most accurate proxy for actual acquisition costs.
} 
prices for a prescription is, on average, $\$ 13.17$, with tenth and ninetieth percentiles of $\$ 4.91$ and $\$ 25.36$, respectively. The coefficient of variation, a common measure of relative dispersion, has a mean of 0.22 in the sample. The empirical analysis that follows will generally focus attention on absolute dispersion since equilibrium price dispersion models typically predict that search-induced variation in price distributions will be independent of scale. This prediction follows from the fact that dispersion is a function of search costs, which are generally modeled as independent of prices. ${ }^{8}$

A striking feature of the data is that pharmacies cannot be easily sorted into "low-price" and "high-price" categories. The contention of this article is that price dispersion can be explained by costly consumer search; however, an important alternative explanation (to which I shall return in Sec. V) is that price differences merely reflect heterogeneity in characteristics of pharmacies. If this were the case, we would expect pharmacies' price rankings to be positively correlated across drugs. That is, if one pharmacy has a superior location or the best service, its prices should be consistently higher than other pharmacies' prices for the drugs in the sample. Table 1 shows that price rankings are far from perfectly correlated across drugs. The table groups the drug prices at each pharmacy into one of three groups: low-price, mid-price, or highprice. With the exception of the Rite-Aid stores, which are consistently among the most expensive, each pharmacy in Middletown seems to have a fair number of drugs in each category. Clearly, no one pharmacy has the lowest prices across the board. In Newburgh, two pharmacies (Price Chopper and Wal-Mart) appear to be substantially cheaper than the others, and Rite-Aid is again consistently more expensive. However, even here, the least expensive provider differs somewhat across drugs.

This remarkable pattern in the data is at odds with an explanation of price dispersion based strictly on pharmacy differentiation. Moreover, it illustrates the difficulty consumers have in predicting which pharmacy will have the lowest price for a given prescription, suggesting an important role for search.

\section{Repeat Purchasing and Observed Price Distributions}

If observed distributions arise from costly consumer search, we expect absolute dispersion and price-cost margins to be decreasing functions of propensity to search. In particular, the theoretical prediction is that

\footnotetext{
${ }^{8}$ Slight modifications to existing models can generate equilibria in which dispersion does depend on production cost levels. In the data analyzed here, measures of absolute dispersion appear to be positively related to average price. The empirical analyses of dispersion as a function of prescription characteristics will therefore control for the apparent influence of price levels on dispersion.
} 
TABLE 1

Price Rankings by Pharmacy A. MidDletown

\begin{tabular}{|c|c|c|c|}
\hline \multirow[b]{2}{*}{ Pharmacy } & \multicolumn{3}{|c|}{ Price Group } \\
\hline & Lowest 3 & Middle 4 & Highest 3 \\
\hline Eckerd & 45 & 103 & 10 \\
\hline Eckerd & 29 & 102 & 27 \\
\hline Immediate & 43 & 54 & 61 \\
\hline K-Mart & 56 & 57 & 45 \\
\hline Medicine Shoppe & 99 & 49 & 10 \\
\hline Price Chopper & 80 & 67 & 11 \\
\hline Rite-Aid & 3 & 11 & 144 \\
\hline Rite-Aid & 2 & 18 & 138 \\
\hline Rx Place & 38 & 104 & 16 \\
\hline Wal-Mart & 79 & 67 & 12 \\
\hline \multicolumn{4}{|c|}{ B. NEWBurgh } \\
\hline & \multicolumn{3}{|c|}{ Price Group } \\
\hline Pharmacy & Lowest 3 & Middle 3 & Highest 3 \\
\hline Ace & 26 & 112 & 30 \\
\hline Hudson & 33 & 106 & 29 \\
\hline Medical Arts & 73 & 65 & 30 \\
\hline Price Chopper & 134 & 27 & 7 \\
\hline Rite-Aid & 4 & 23 & 141 \\
\hline Rite-Aid & 10 & 45 & 113 \\
\hline Rite-Aid & 18 & 34 & 116 \\
\hline Rx Place & 64 & 70 & 34 \\
\hline Wal-Mart & 142 & 22 & 4 \\
\hline
\end{tabular}

frequently purchased prescriptions (for which consumers' incentives to price-shop are strongest) should exhibit lower markups and less dispersion.

To obtain a measure of purchase frequency, I used information from Mosby's GenRx (1998) on typical dosage and duration of therapy to calculate the expected number of times each prescription would need to be purchased in the course of one year. For example, the typical dosage of the antihypertensive Vasotec (10 $\mathrm{mg}$ ) is one per day, with therapy lasting for 365 days. I therefore calculate that a prescription for 60 tablets would ordinarily need to be purchased $(1 \times 365) / 60=6.08$ times, or roughly once every two months. I call this variable PFREQ (purchase frequency). When the typical duration of therapy is less than one month (e.g., for antibiotics), the purchase frequency variable is equal to one. ${ }^{9}$ Most of the drugs with a purchase frequency of one are penicillins, cephalosporins, and erythromycins. In a handful of cases, the calculated

${ }^{9} \mathrm{I}$ assume that consumers with acute conditions do not anticipate needing to purchase the same prescription again within the next year. 
frequency of purchase implied a need to purchase the prescription three times a month $(\mathrm{PFREQ}=36)$. To prevent these few drugs from driving the results, I capped the PFREQ variable at 24, so that maintenance medications are assumed to be purchased at most twice a month. ${ }^{10}$

Note that this measure of purchase frequency is richer than a measure based on duration of therapy alone. As measured, the PFREQ variable can capture differences in shopping incentives between a prescription that is purchased twice a month and a prescription that is purchased every three months, even if both are used for therapy of the same expected duration. ${ }^{11}$

\section{A. Dispersion}

On the basis of the arguments outlined previously, we expect absolute dispersion of prescription prices to decrease with purchase frequency, suggesting the following simple regression:

$$
\begin{aligned}
\operatorname{RANGE}_{i j}= & \beta_{0}+\beta_{1} \mathrm{PFREQ}_{i}+\beta_{2} \mathrm{AWP}_{i}+\beta_{3} \mathrm{BR}_{i}+\beta_{4} \mathrm{BR}_{i} \\
& +\beta_{5} \mathrm{NEWB}_{i}+\sum_{k=6}^{25} \beta_{k} D_{i k}+\epsilon_{i j} .
\end{aligned}
$$

The dependent variable is the price range (across pharmacies in town $j$ ) for the prescription. The variable AWP is the drug's acquisition cost (based on its listed average wholesale price) and is included to control for the potential impact of price levels on dispersion. ${ }^{12}$ The terms BR1 and BR2 are dummies for two kinds of brand-name drugs: those that face competition from generic equivalents and those that do not. This distinction captures the idea that consumers who choose to buy brandname prescriptions even when generics are available may be particularly insensitive to price (and by extension not inclined to price-shop), and this may be reflected in the distribution of prices. The variable NEWB is a dummy variable for Newburgh, and the $D$ variables are indicators for 20 categories of drug therapy. They are included as crude controls

\footnotetext{
${ }^{10}$ Results from regressions with and without the cap on PFREQ differ very little. Although it is possible that some prescriptions are filled three times a month (for instance, because of narcotics regulations and overdose issues), conversations with pharmacists suggested that this is unusual.

${ }^{11}$ Unlike customers with insurance coverage, cash-paying customers are not typically constrained to purchase medications one month at a time and in fact are more inclined to ask their doctors to issue multimonth prescriptions. Although this is less common than multimonth prescriptions, some customers also fill prescriptions for maintenance medications twice or more per month.

${ }^{12}$ Listed AWPs are an imperfect proxy for actual acquisition costs. In reality, different pharmacies may pay different wholesale prices for the same drug (e.g., if wholesalers pricediscriminate); the possibility that dispersion at the retail level simply reflects dispersion at the wholesale level is discussed in Sec. V.
} 
TABLE 2

Price Dispersion and Purchase Frequency

\begin{tabular}{|c|c|c|c|c|}
\hline & \multicolumn{4}{|c|}{ Dispersion MEASURE } \\
\hline & $\begin{array}{l}\text { Range } \\
(1)\end{array}$ & $\begin{array}{c}\text { Standard } \\
\text { Deviation } \\
\quad(2)\end{array}$ & $\begin{array}{l}\text { Residual } \\
\text { Range } \\
\text { (3) }\end{array}$ & $\begin{array}{c}\text { Residual } \\
\text { Standard } \\
\text { Deviation } \\
\text { (4) }\end{array}$ \\
\hline Purchase frequency & $\begin{array}{l}-.336 \\
(.123)\end{array}$ & $\begin{aligned}-.173 \\
(.076)\end{aligned}$ & $\begin{array}{l}-.266 \\
(.061)\end{array}$ & $\begin{array}{l}-.102 \\
(.016)\end{array}$ \\
\hline Wholesale cost & $\begin{array}{l}.280 \\
(.033)\end{array}$ & $\begin{array}{l}.180 \\
(.020)\end{array}$ & $\begin{array}{l}.215 \\
(.043)\end{array}$ & $\begin{array}{l}.069 \\
(.014)\end{array}$ \\
\hline $\begin{array}{l}\text { Branded with generic } \\
\text { competition }\end{array}$ & $\begin{array}{l}-.803 \\
(1.037)\end{array}$ & $\begin{aligned}-1.480 \\
(.641)\end{aligned}$ & $\begin{array}{r}-1.842 \\
(.861)\end{array}$ & $\begin{array}{c}-.362 \\
(.248)\end{array}$ \\
\hline $\begin{array}{l}\text { Branded without ge- } \\
\text { neric competition }\end{array}$ & $\begin{array}{r}-1.505 \\
(2.108)\end{array}$ & $\begin{array}{l}-2.010 \\
(1.303)\end{array}$ & $\begin{array}{r}-1.967 \\
(1.060)\end{array}$ & $\begin{array}{r}-.772 \\
(.339)\end{array}$ \\
\hline Newburgh dummy & $\begin{array}{r}-2.686 \\
(.633)\end{array}$ & $\begin{array}{r}-3.172 \\
(.314)\end{array}$ & $\begin{array}{r}-1.493 \\
(.791)\end{array}$ & $\begin{array}{l}-.916 \\
(.271)\end{array}$ \\
\hline Constant & $\begin{array}{l}20.070 \\
(4.343)\end{array}$ & $\begin{array}{c}7.321 \\
(2.563)\end{array}$ & $\begin{array}{l}14.570 \\
(1.062)\end{array}$ & $\begin{array}{l}5.283 \\
(.448)\end{array}$ \\
\hline$R^{2}$ & .371 & .447 & .258 & .253 \\
\hline$\hat{\rho}$ & .338 & .585 & .149 & .648 \\
\hline
\end{tabular}

for the composition of the drug's users; price distributions will be sensitive to different demographic groups' differing propensities to search. Including the drug class dummies accounts for the possibility, for instance, that users of antiarthritics are inherently more (or less) prone to price-shop than users of oral contraceptives.

Column 1 of table 2 reports the regression results. The estimates are obtained using generalized least squares (GLS) to account for the fact that errors for a given drug may be correlated across cities (i.e., $\left.E\left[\epsilon_{i, \text { Middletown }} \epsilon_{i, \text { Newburgh }}\right] \neq 0\right)$. As expected, the estimated coefficient on the purchase frequency variable is negative and statistically significant. The estimate indicates that (other things being equal) the price range of a drug that must be purchased monthly will be 28 percent smaller than if it were a one-time therapy. This is consistent with the hypothesis that consumers' increased propensity to price-shop for frequently purchased drugs constrains pharmacy prices to lie within a narrower range.

Column 2 of the table lists coefficients from a regression on the standard deviation, an alternative measure of absolute dispersion. I include this as a check: since the range depends on the extremes of the price distribution, it may be particularly sensitive to outliers or mistakes in reporting. As the table shows, the negative relationship between price dispersion and purchase frequency is consistent across the two measures. The relationship holds for measures of relative dispersion as well: es- 
timates using the coefficient of variation (not reported) suggest that drugs purchased monthly exhibit 20 percent less relative dispersion than one-time purchases. The pattern described by the regression results in table 2 is also remarkably robust to alternative definitions of the purchase frequency variable. The basic result that repeatedly purchased maintenance drugs have tighter price distributions than one-time prescriptions is the same regardless of whether PFREQ is capped at 12 or defined as a binary or categorical variable.

The coefficients on the brand dummies suggest that prices are more dispersed for generics than for branded drugs, although the estimates are not statistically significant. Higher dispersion for generic drugs at the retail level may be a reflection of dispersion at the wholesale level; I consider this possibility in the next section. The hypothesis that the coefficients on the two brand dummies are equal cannot be rejected statistically; at least in this set of regressions, there does not seem to be evidence that prices are set differently for branded drugs with generic equivalents available versus those with no equivalents available.

The estimates also indicate that prices are less dispersed in Newburgh than in Middletown, in spite of the fact that the two cities are ostensibly quite similar. That the difference is statistically distinguishable may suggest a role for market-specific characteristics in determining equilibrium price distributions; identifying how market characteristics affect dispersion is an interesting topic for future research.

The estimated drug class effects (not reported), which are included primarily as controls, give some evidence that dispersion depends on the drug's intended use. Ceteris paribus, prices are most dispersed for drugs used to treat anxiety and hypertension, and least dispersed for prescriptions used to treat infections and diabetes. Dispersion is also relatively low for contraceptives, which is consistent with reports that contraceptives are among the most heavily price-shopped drugs.

Finally, note that the estimated correlation of the residuals across cities $(\hat{\rho})$ is significantly positive. This also is consistent with a consumer search explanation: unobserved, drug-specific determinants of search intensity will generate a positive correlation in the estimation residuals as long as they affect search analogously in both towns (which seems reasonable to assume).

\section{B. Dispersion after Correcting for Pharmacy Effects}

Since price differences may depend to some extent on differences in the pharmacies themselves, the relevant dispersion measure may be one that measures price dispersion after accounting for pharmacy heterogeneity. For instance, one can think of purging the dispersion measure of price variation arising from pharmacy differences by calculating the 
dispersion in the residuals (across pharmacies for each drug) from a regression of price on drug and pharmacy fixed effects. This "corrected" measure of dispersion can then be used as the dependent variable in a regression on search-related variables.

Results from using this alternative approach to measuring dispersion are reported in columns 3 and 4 of table $2 .{ }^{13}$ The pattern of coefficients is essentially the same as reported in columns 1 and 2: dispersion is negatively related to purchase frequency. The estimated effect of repeat purchasing is statistically significant for each of the alternative measures of absolute dispersion; accounting for pharmacy differences before measuring dispersion simply reduces the magnitude of the estimated effect of repeat purchases. This set of results predicts that the price range for a one-time purchase will be 22 percent larger than the range for a monthly prescription (other things being equal), as opposed to the 28 percent estimated previously.

The important result here is that variables related to consumer search (in particular, the frequency of purchase) have explanatory power even after pharmacy differences are taken into account. I interpret this as strengthening the case that price dispersion in these markets cannot be "explained away" by a product heterogeneity story; at least some of the dispersion appears to derive from the consumer search environment.

\section{Margins}

The intuitive prediction from search theory is that prescriptions for which consumers are more inclined to price-shop should exhibit lower price-cost margins. One therefore expects average margins to be negatively related to purchase frequency. For the researcher, calculating exact margins is impossible because costs are unobservable. However, an estimate of each prescription's cost can be constructed using data on average wholesale prices. I assume that cost is equal to 85 percent (70 percent) of listed AWP for branded (generic) drugs, plus a $\$ 3.00$ fixed dispensing cost. Although crude, this measure of cost will not be wildly inaccurate. Recent studies using actual pharmacy invoices have estimated that listed AWP overstates actual acquisition costs by an average of 15 percent for branded drugs and 30 percent for generics (Conlan 1996; FDC Reports 1997). The $\$ 3.00$ dispensing cost reflects how pharmacists typically report their cost structure and also how pharmacies

\footnotetext{
${ }^{13}$ The econometric estimation is done in one step, by stacking the first-order conditions from the two least-squares problems-price regressed on drug and pharmacy fixed effects, and the range (across pharmacies) of the resulting residuals regressed on purchase frequency, etc.-and estimating the parameters using a generalized method of moments routine.
} 
TABLE 3

Average Margins and Purchase Frequency

\begin{tabular}{|c|c|c|c|}
\hline & \multicolumn{3}{|c|}{ DePendent Variable } \\
\hline & $\begin{array}{l}\text { Average } \\
\text { Margin } \\
\text { (1) }\end{array}$ & $\begin{array}{l}\text { Average } \\
\text { Price } \\
\text { (2) }\end{array}$ & $\begin{array}{c}\text { Average } \\
\text { Relative } \\
\text { Margin } \\
\text { (3) }\end{array}$ \\
\hline Purchase frequency & $\begin{array}{c}-.262 \\
(.102)\end{array}$ & $\begin{array}{l}-.137 \\
(.105)\end{array}$ & $\begin{array}{c}.001 \\
(.003)\end{array}$ \\
\hline Wholesale cost & $\ldots$ & $\begin{array}{l}.994 \\
(.032)\end{array}$ & $\ldots$ \\
\hline $\begin{array}{l}\text { Wholesale cost } \times \text { generic } \\
\text { dummy }\end{array}$ & $\ldots$ & $\begin{array}{r}-.208 \\
(.059)\end{array}$ & $\ldots$ \\
\hline $\begin{array}{l}\text { Branded with generic } \\
\text { competition }\end{array}$ & $\begin{array}{l}2.101 \\
(.720)\end{array}$ & $\begin{array}{l}-.668 \\
(1.056)\end{array}$ & $\begin{array}{c}-.235 \\
(.020)\end{array}$ \\
\hline $\begin{array}{l}\text { Branded without generic } \\
\text { competition }\end{array}$ & $\begin{array}{c}3.415 \\
(1.660)\end{array}$ & $\begin{array}{l}-.123 \\
(1.891)\end{array}$ & $\begin{array}{r}-.255 \\
(.046)\end{array}$ \\
\hline Newburgh dummy & $\begin{array}{l}1.681 \\
(.174)\end{array}$ & $\begin{array}{l}1.648 \\
(.140)\end{array}$ & $\begin{array}{l}.047 \\
(.005)\end{array}$ \\
\hline Constant & $\begin{array}{l}12.69 \\
(2.435)\end{array}$ & $\begin{array}{l}11.86 \\
(2.581)\end{array}$ & $\begin{array}{l}.463 \\
(.068)\end{array}$ \\
\hline$R^{2}$ & .229 & .895 & .510 \\
\hline$\hat{\rho}$ & .915 & .936 & .898 \\
\hline
\end{tabular}

are usually reimbursed by government and commercial third-party payers (see, e.g., Tootelian and Gaedeke 1993). Moreover, as will be discussed in the next section, differences in cost across pharmacies due to price discrimination by wholesalers are likely to be small. ${ }^{14}$ The magnitudes of markups based on this assumption about costs seem plausible: most are in the $\$ 2-\$ 10$ range, with a thin tail of drugs exhibiting relatively high average margins.

Column 1 of table 3 reports the estimated coefficients from a regression of average margins on purchase frequency, with additional controls entering as in the dispersion regressions. The coefficient on PFREQ is negative and statistically significant: margins are indeed lower for prescriptions that are purchased repeatedly. The estimate suggests that absolute margins are about 37 percent lower for drugs that are purchased monthly versus drugs that are purchased only once, other things being equal.

Results from a slightly more flexible specification are reported in column 2 of the table. Using the average absolute margin as the dependent variable in a linear regression is tantamount to using average

\footnotetext{
${ }^{14}$ Even if differences in cost across pharmacies were substantial, the average wholesale price will likely still be an adequate measure of the average cost across pharmacies, which is what is needed for this analysis.
} 
price as the dependent variable and restricting the coefficient on prescription cost to be one. I relax this restriction by regressing average price on purchase frequency and AWP, the prescription's wholesale cost. An interaction of AWP with a generic dummy is also included to account for the reported possibility that average discounts off listed wholesale prices are larger for generics than for branded drugs. The relationship between average price and purchase frequency is again seen to be negative, although it is no longer statistically significant. The coefficient on the interaction of AWP with the generic dummy provides some support for the assumption that list prices are more overstated for generics than for branded drugs.

Finally, column 3 of table 3 reports results when relative margins, $(p-c) / p$, are used as the dependent variable. The estimated coefficient on PFREQ is statistically indistinguishable from zero, which is perhaps not surprising: while search models generally predict that average $a b$ solute markups will depend negatively on search intensity, conclusions about the behavior of relative margins are not as clear.

\section{Covariation of Dispersion and Margins}

An important prediction of search models is that measures of margins and absolute dispersion should move together in response to changes in the search environment. Therefore, if price distributions depend on consumer search, we expect a positive correlation between the residuals from the dispersion and margin regressions, since the effects of unobserved shifters of search costs-that is, drug characteristics that affect search but are not accounted for in the regressions-should have the same sign. In fact, the simple correlation of the residuals is .39, which is consistent with the idea that unobserved determinants of search cause margins and dispersion to move together. ${ }^{15}$

A presumption that the residuals from the dispersion and margin regressions are positively correlated implies that the regressions would be most appropriately estimated using Zellner's (1962) method of seemingly unrelated regressions. Results from seemingly unrelated regression estimation confirm the results in tables 2 and 3, indicating that both margins and dispersion decline with a prescription's frequency of purchase. The magnitude of the estimated impact of repeat purchasing is slightly larger than implied previously: all else equal, the price range

${ }^{15}$ An alternative interpretation of the observed correlation is provided by the oligopoly model of Perloff and Salop (1986). In their model, consumers' uncertainty about actual prices (as measured by the variance in their estimates of price) affects the elasticity of the demand curve facing any given firm. As uncertainty shrinks, demand becomes more elastic, leading to lower markups. If uncertainty is correlated with the actual price range (as seems reasonable), their model would predict the correlation described here. 
(markup) for a prescription that is purchased monthly will be 34 percent (41 percent) lower than for a one-time prescription. Most important for the argument here, the estimated correlation between the regression residuals is .398, and a Lagrange multiplier test overwhelmingly rejects the hypothesis that the residuals are independent.

\section{Alternative Explanations}

The evidence presented in Section IV strongly suggests that the dispersion in prescription prices can be explained by costly consumer search. In this section I consider the potential importance of two alternative explanations for the price variation: pharmacy heterogeneity and cost heterogeneity.

\section{A. Pharmacy Heterogeneity}

Although prescriptions themselves are almost perfectly homogeneous (no matter where the prescription is filled, it will be the same drug in the same amount), pharmacies can and do differentiate themselves along service dimensions. Some offer free delivery, some have drivethrough windows, some more conspicuously counsel patients about drug interactions and side effects, and some pharmacists simply smile more. Spatial differentiation may also play a role in determining prices since consumers will prefer to patronize more conveniently located pharmacies.

However, the pricing patterns illustrated in table 1 suggest that the observed dispersion cannot result entirely from differentiation at the pharmacy level: pharmacies' price rankings show very little correlation across drugs. Moreover, general observations made during visits to the pharmacies are also inconsistent with an explanation of pure product heterogeneity. In both Middletown and Newburgh, the pharmacies that appeared most attractive on the basis of nonprice considerations (e.g., newer facility, central location, etc.) did not seem to charge premia for superior service or convenience; on the contrary, their prices tended to be lower than their competitors'.

While the foregoing observations suggest that pharmacy heterogeneity alone cannot explain the patterns in the data, we expect price differences to be at least partially attributable to differences in pharmacies. One way to assess the role of differences in pharmacies in explaining price dispersion is to ask how much of the unexplained variation in prices across stores is absorbed by pharmacy fixed effects. Column 1 of table 4 reports the $\bar{R}^{2}$ from regressions of prescription prices on the following sets of explanatory variables: (1) drug fixed effects, (2) drug and pharmacy fixed effects, and (3) drug and pharmacy 
TABLE 4

Explaining Price Variation with Pharmacy Fixed Effects

\begin{tabular}{l}
\hline \hline \\
\cline { 2 - 3 }
\end{tabular}

fixed effects, with pharmacy effects interacted with dummies for 20 categories of primary indication. Columns 2 and 3 of the table show the mean and standard deviation of the residual magnitudes.

How much explanatory power is added by including pharmacy effects? If price differences reflect pharmacy heterogeneity, we expect pharmacy fixed effects to substantially improve the fit of the price regression. As the table shows, adding pharmacy effects does increase the $R^{2}$, explaining 33 percent of the variation left unexplained by the regression with only drug fixed effects. In other words, allowing for pharmacy-specific differences accounts for roughly one-third of the observed price dispersion.

In fact, the estimate of 33 percent may overstate the significance of pharmacy heterogeneity in generating price differences. Regressions explicitly accounting for service characteristics yield weak results, suggesting that the explanatory power of pharmacy fixed effects is probably not fully attributable to differences in pharmacy quality. The apparent explanatory power of pharmacy differences will be inflated because some "pure" price dispersion (unrelated to pharmacy differences) will nevertheless be absorbed by the pharmacy fixed effects. In particular (and in the language of equilibrium dispersion models), if firms' draws from the equilibrium price distributions are correlated across prescriptions, then pharmacy effects will improve the fit of the price regression even if pharmacies' characteristics are identical.

The third regression reported in table 4 includes pharmacy interactions with drug types, to account for the possibility that some pharmacies have the best service for some types of medication but relatively worse service for others. Also, a pharmacy may be the most conveniently located for a high demographic concentration of the users of a particular type of drug (e.g., the pharmacy located nearest a retirement community may be able to charge relatively high prices for arthritis and heart med- 
ications). As the table shows, allowing for these interaction effects improves the fit of the regression only slightly. Pharmacy/drug class interactions explain an additional 4 percent of the variation of prescription prices about their means. ${ }^{16}$

\section{B. Cost Heterogeneity}

Without access to hard data on pharmacies' costs, it is difficult to ascertain their precise importance in generating retail price differences. However, available evidence suggests that differences in drug acquisition costs are probably too small to explain the price dispersion observed here. One reason acquisition costs may vary across pharmacies is that different types of pharmacies may receive unequal discounts from wholesalers. However, data on average wholesale prices suggest that acquisition costs vary only slightly across chain pharmacies, independents, and food stores, the only types of pharmacies in these data. For instance, work by Ellison (1997) on antibiotics suggests that chain stores pay roughly 2 percent less than independents and roughly 5 percent less than food stores. If this pattern is true of pharmacies in Middletown and Newburgh, we should expect chain pharmacies to have lower prices (on average) than their independent and food store counterparts. In fact, the opposite is true: of the three pharmacy types, chains have the highest prices on average. While this clearly does not rule out the possibility that different pharmacies in our sample negotiate different discounts, it does suggest that such discounts probably do not explain the observed price variation.

If retail price dispersion reflects dispersion at the wholesale level, we should expect prices for multisource drugs to be more dispersed than prices for single-source drugs. For branded (single-source) drugs, the pharmacies in the sample probably purchase from the same regional distributor. However, in the case of generic drugs (for which there are multiple potential suppliers), acquisition costs will differ if there is price dispersion at the wholesale level and pharmacies do not all purchase from the lowest-price provider. ${ }^{17}$ To the extent that this is true, retail prices for branded drugs should be less dispersed than prices for their

\footnotetext{
${ }^{16}$ The categorization of drugs into 21 types of therapy may fail to capture important unobserved drug characteristics. I explore this issue in a previous version of this paper (Sorensen 1999) by testing whether drug groupings inferred from price patterns in Newburgh have explanatory power for prices in Middletown. When interacted with pharmacy effects, the drug groupings absorb an additional 8 percent of the unexplained price variation (beyond the 33 percent explained by pharmacy effects alone).

${ }^{17}$ Listed AWPs for multisource drugs suggest that wholesale prices may vary somewhat across manufacturers. However, pharmacies obviously have strong incentives to seek out the lowest-cost provider, or at least demand that their chosen distributor match the lowest price.
} 
generic counterparts, reflecting the underlying dispersion in acquisition costs. The coefficients on the brand dummies in the regressions of table 2 give some support for this hypothesis. Particularly when dispersion is measured after accounting for pharmacy differences, prices appear to be significantly more dispersed for generic drugs than for branded drugs, suggesting that heterogeneity in acquisition costs may play some role in explaining dispersion at the retail level. However, such cost heterogeneity is unlikely to be the principal source of the dispersion since dispersion for single-source drugs is still substantial. Moreover, the negative relationship between dispersion and purchase frequency persists even when the estimation includes only single-source drugs.

\section{Conclusion}

The basic fact described in this paper is that dispersion in cash prices for prescription drugs is substantial, even across pharmacies within small local markets. The evidence analyzed here suggests that dispersion arises at least in part from the nature of the consumer search environment. Measures of absolute dispersion and price-cost margins display a negative, statistically significant relationship with the prescription's purchase frequency. This empirical regularity fits well with the predictions of models based on consumer search: expected benefits of search are highest for prescriptions that must be purchased frequently, and equilibrium prices decrease (and become less dispersed) in response to consumers' increased propensities to price-shop for such prescriptions. Moreover, after one accounts for the effects of purchase frequency, residual variation in margins and dispersion is consistent with an explanation based on unobserved differences in search intensity across drugs.

An important question addressed in the paper is how much of the observed price dispersion (if any) can be attributed to pharmacy heterogeneity. I present evidence suggesting that although pharmacy differences explain roughly one-third of the price variation, price patterns are not consistent with a strict differentiated products story.

The extent to which price dispersion is related to consumer search has important implications for policies affecting the costs of acquiring price information. If dispersion is generated by imperfect price information, programs or policies that centralize price information (or otherwise improve access to it) may result in lower prices for consumers. For example, price advertising by pharmacies is often prohibited by law. The finding here that price distributions are related to consumer search suggests that the absence of such advertising may result in higher prices and more price dispersion than would otherwise prevail. 


\section{References}

Benabou, Roland. "Search Market Equilibrium, Bilateral Heterogeneity, and Repeat Purchases." J. Econ. Theory 60 (June 1993): 140-58.

Burdett, Kenneth, and Judd, Kenneth L. "Equilibrium Price Dispersion." Econometrica 51 (July 1983): 955-69.

Carlson, John, and McAfee, R. Preston. "Discrete Equilibrium Price Dispersion." J.P.E. 91 (June 1983): 480-93.

Conlan, Michael F. "Go Figure! National Association of Chain Drug Stores Criticizes Federal Report on Drug Acquisition Costs." Drug Topics 140 (October 7, 1996): 108.

Dahlby, Bev, and West, Douglas S. "Price Dispersion in an Automobile Insurance Market.” J.P.E. 94 (April 1986): 418-38.

Ellison, Sara Fisher. "Recent Patterns in Antibiotics Pricing." Manuscript. Cambridge: Massachusetts Inst. Tech., September 1997.

FDC Reports 59 (January 13, 1997), p. 7.

Fishman, Arthur, and Rob, Rafael. "The Durability of Information, Market Efficiency and the Size of Firms." Internat. Econ. Rev. 36 (February 1995): 19-36.

Mosby's GenRx. 8th ed. St. Louis: Mosby Year Book, 1998.

Perloff, Jeffrey M., and Salop, Steven C. "Firm-Specific Information, Product Differentiation, and Industry Equilibrium.” Oxford Econ. Papers 38 (suppl.; November 1986): 184-202.

Pratt, John W.; Wise, David A.; and Zeckhauser, Richard J. "Price Differences in Almost Competitive Markets." Q.J.E. 93 (May 1979): 189-211.

Retail Pharmacy Practice Management. Chapel Hill, N.C.: Nat. Assoc. Retail Druggists, 1989.

Salop, Steven C., and Stiglitz, Joseph E. "The Theory of Sales: A Simple Model of Equilibrium Price Dispersion with Identical Agents." A.E.R. 72 (December 1982): 1121-30.

Sorensen, Alan. "Empirical Studies of Oligopolistic Pricing and Heterogeneous Consumer Search.” Ph.D. dissertation, Massachusetts Inst. Tech., 1999.

Stahl, Dale O., II. "Oligopolistic Pricing with Sequential Consumer Search." A.E.R. 79 (September 1989): 700-712.

Stigler, George J. “The Economics of Information.” J.P.E. 69 (June 1961): 213-25.

Tootelian, Dennis H., and Gaedeke, Ralph M. Essentials of Pharmacy Management. St. Louis: Mosby Year Book, 1993.

Van Hoomissen, Theresa. "Price Dispersion and Inflation: Evidence from Israel." J.P.E. 96 (December 1988): 1303-14.

Villas-Boas, J. Miguel. "Models of Competitive Price Promotions: Some Empirical Evidence from the Coffee and Saltine Crackers Markets." J. Econ. and Management Strategy 4 (Spring 1995): 85-107.

Zellner, Arnold. "An Efficient Method of Estimating Seemingly Unrelated Regressions and Tests for Aggregation Bias.” J. American Statis. Assoc. 57 (June 1962): 348-68. 